\title{
A regulatory defect of constitutive no-synthase in islet endothelial cells correlates with probability of disease manifestation in BBdp rats
}

\author{
C.V. Suschek ${ }^{1}$, E. Bonmann ${ }^{2}$, V. Kolb-Bachofen ${ }^{1}$ \\ ${ }^{1}$ Institute of Immunobiology, MED-Heinrich-Heine-University of Düsseldorf, Düsseldorf, Germany \\ ${ }^{2}$ Neurologische Klinik der Ruprecht-Karls-Universität, Heidelberg, Germany
}

\begin{abstract}
Aims/hypothesis. Type I (insulin-dependent) diabetes mellitus is characterised by leucocyte infiltration of pancreatic islets and a progressive destruction of insulin-producing beta cells. As endothelial nitric oxide production is known to regulate adhesion molecule expression and leucocyte permeation, we examined the activity and expression of the constitutive nitric oxide synthase (ecNOS) of islet endothelial cells from prediabetic BBdp rats.

Methods. Cultures of aortic endothelial cells and islet capillary endothelial cells were established from young normoglycaemic BBdp rats, Wistar rats and diabetes-resistant BBdr rats, all matched for age. Nitrite and citrulline production was measured in all culture supernatants as indicators for ecNOS activities. Expression of $e c$ NOS mRNA was assessed by reverse transcription-polymerase chain reaction.

Results. In contrast to those of the aorta, the Wistar rat islet derived endothelial cells exhibited a strong positive correlation of $e c$ NOS activity with the culture medium glucose concentration but none of the
\end{abstract}

BB rat-derived islet endothelial cells showed a similar glucose-responsiveness. Furthermore, at physiological as well as at increased glucose concentrations islet endothelia from all BBdp rats exhibited a considerable decrease in $e c$ NOS activity by a factor of 3 to 6 , indicating a specific dysfunction which is also found for the inducible nitric oxide synthase activity after cytokine challenge but effects were less (2.5 to 3 times) dramatic. In contrast, aorta endothelia from all rats exhibited identical ecNOS activities and no glucose responsiveness. We also found a correlation between ecNOS activities and ecNOS-mRNA expression and can exclude the involvement of the inducible isoform.

Conclusion/interpretation. A reproducible and highly significant dysfunction of islet ecNOS expression and activity in young normoglycaemic BBdp rats, which strongly correlates with the probability for disease manifestation is shown. [Diabetologia (1999) 42: 457-464]

Keywords Endothelial nitric oxide synthase, islet endothelial cells, nitric oxide, BBdp rat.
Received: 13 October 1998 and in revised from: 7 December 1998

Corresponding author: Professor V. Kolb-Bachofen, Institute of Immunobiology, MED-Heinrich-Heine-University, P.O. Box 1010 07, D-40001 Düsseldorf, Germany

Abbreviations: AEC, Aorta endothelial cells; IEC, islet endothelial cells; NO, nitric oxide; NOS, nitric oxide synthase; $e c$ NOS, endothelial constitutive nitric oxide synthase; $i$ NOS, inducible nitric oxide synthase; ECGS, endothelial cell growth supplement; HBSS, Hanks balanced salt solution; vWF, Willebrand Factor; TBS, TRIS buffered saline; RT, reverse transcription.
Type I (insulin-dependent) diabetes is an immune-mediated disease $[1,2]$ characterised by early leucocyte accumulation around and then infiltration of pancreatic islets [3], concomitant with a progressive destruction of insulin-producing beta cells [4]. The mechanisms leading to the accumulation of circulating leucocytes at the sites of pancreatic islets are poorly characterised. Prior to this accumulation, circulating mononuclear cells must extravasate, a process dependent on leucocyte interaction with the local endothelium $[5,6]$.

It has been postulated that malfunction of the vascular endothelium represents an early pathological 
process in diabetes [7]. Indeed, the strong periinsulitis found early during diabetes development in NOD mice points to increased local adhesiveness of endothelia. Vascular function abnormalities, such as haemodynamic changes [8] and increased vascular permeability [9], as well as vascular structural lesions [10], can develop early in both human and experimental diabetes [11]. Data from adhesion studies show that, in the diabetic pancreas, binding of lymphocytes to the endothelium of pancreatic blood vessels is increased [12]. In addition, hypercoagulability [13] and platelet preactivation [14] have been described in human patients. An increasing amount of data point to a key role for endothelium-derived nitric oxide (NO) in blood pressure regulation [15], inhibition of platelet aggregation and platelet adhesion $[16,17]$, and in inflammation $[18,19]$ by modulating leucocyte adhesion to the endothelium, an essential early step in tissue inflammation [20].

Nitric oxide and equal amounts of citrulline are synthesised from the guanidino nitrogen of $\mathrm{L}$-arginine by the nitric oxide synthases (NOS). Endothelial cells can express two different isotypes of the NO-synthases: the constitutively expressed calcium/calmodulindependent endothelial enzyme (ecNOS) and, after proinflammatory cytokine challenge, the inducible isoenzyme inducible nitric oxide synthase $(i \mathrm{NOS})$ [21]. Endothelium-derived NO regulates platelet aggregation and platelet adhesion and in addition is an important endogenous modulator of leucocyte adherence to the endothelium [22, 23]. Impairment of endothelial NO production results in increased leucocyte adhesion and migration as a prerequisite for infiltrative processes.

We have shown previously that comparatively high $e c \mathrm{NOS}$-activities are found in cultures of islet capillary endothelial cells obtained from Wistar-rats which are regulated by the glucose concentrations of the culture media [24].

In this study we compared the ecNOS-mediated NO production of resident aorta and islet capillary endothelial cell cultures obtained from young Wistar rats, prediabetic BBdp rats and BBdr rats that are resistant to diabetes. The results obtained with these cells show a marked heterogeneity among the regulation of ecNOS-activities in endothelial cells obtained from different blood vessel types as well as between the different rat strains. We found a reproducible and high impairment of $e c$ NOS-activities in islet endothelia derived from young normoglycaemic BBdp rats which is not seen in Wistar or BBdr rats. This defect may contribute to islet infiltration and thus represent an important factor in the development of Type I diabetes.

\section{Materials and methods}

Reagents. Endothelial cell growth supplement (ECGS), type I collagen, collagenase (from $\mathrm{Cl}$. histolyticum), urease Type VII and rabbit anti-human von Willebrand Factor (vWF) antiserum were from Sigma (Deisenhofen, Germany). Monoclonal antibodies Ox2, Ox43, and anti-rat-CD31 were from Serotec (Camon, Wiesbaden, Germany) the anti-ecNOS antibody from Transduction Laboratories (Lexington, Ky., USA). Peroxidase-conjugated porcine anti-rabbit IgG from Dako (Hamburg, Germany), and peroxidase-conjugated goat anti-mouse $\mathrm{IgG}$ was from Zymed Laboratories, (San Francisco, Calif., USA). Trypsin, EDTA, fetal calf serum (FCS, endotoxin free), Taq-polymerase, Rtase, and the oligo $\mathrm{dT}_{16}$-primer were purchased from Boehringer Mannheim (Mannheim, Germany). We obtained RPMI-1640 (endotoxin free) from Gibco Laboratories (Eggenstein, Germany). 3,3'-diaminobenzidine from Serva (Heidelberg, Germany) and Ficoll 400 from Pharmacia (Uppsala, Sweden). Some batches of RPMI-1640 were prepared from individual constituents (all analytical grade, Sigma) according to the standard recipe using $\mathrm{CaCl}_{2}$ instead of $\mathrm{Ca}\left(\mathrm{NO}_{3}\right)_{2}$ and adding glucose at the concentrations indicated.

Animals. Male Wistar rats ( $n=10$; about 30 days old) were obtained from our University breeding facility. Young normoglycaemic male BBdp rats $(n=6 ; 30$ days old $)$ and $\mathrm{BBdr}$ rats ( $n=6 ; 30$ days old) were obtained from Mollegard Breeding Centre (Ejby, Denmark). Diabetes incidence in the BBdp rat colony at the time of purchase was $80 \%$ and of the BBdr rats less than $3 \%$. All animals received a standard diet and tap water ad libitum.

Endothelial cells. Islet endothelial cells or vascular endothelial cells were isolated from pancreatic islets or from rat aortic rings by outgrowth on a collagen type I matrix as described previously [21, 24]. Rats were anaesthetised, the thoracic aorta was removed, rinsed in Hanks balanced salt solution (HBSS), cleaned of periadventitial fat and connective tissue and then cut into rings approximately $2 \mathrm{~mm}$ in width. Pancreatic islets were harvested by hand picking after ductal injection of collagenase and subsequent centrifugation of the dispersed tissue on a Ficoll density gradient [25].

Aortic segments or hand-picked whole islets were placed on top of a collagen gel $(1.8 \mathrm{mg}$ collagen $/ \mathrm{ml})$ in 24 -well tissue culture plates and incubated in RPMI 1640 with $20 \%$ FCS and $100 \mu \mathrm{g} \mathrm{ECGS} / \mathrm{ml}$ in a humidified incubator at $37^{\circ} \mathrm{C}$ in a $95 \%$ air:5\% $\mathrm{CO}_{2}$ atmosphere for 5 to 7 days. Aortic explants or islets were removed, cells were detached with $0.25 \%$ collagenase in HBSS and replated onto plastic culture dishes in RPMI 1640 with $20 \%$ FCS. Cells were subcultured for up to 8 passages and removal from culture dishes for each passage was carried out by treatment with $0.05 \%$ trypsin: $0.02 \%$ EDTA in isotonic $\mathrm{NaCl}$ for $3 \mathrm{~min}$.

Growth rates of endothelial cells and viability. Aorta endothelial cells (AEC) and islet endothelial cells (IEC) were seeded and grown under identical conditions. Cells were quantified at different times by neutral red staining [26]. In the linear growth phase AEC exhibited a doubling time of approximately $24 \mathrm{~h}$, whereas IEC were slower with a generation time of approximately $30 \mathrm{~h}$. Viability of endothelial cells was controlled routinely at the beginning and the end of every experiment using trypan blue exclusion.

Cellular characterisation of cultured endothelial cells. Cells were passaged from tissue culture dishes onto sterile glass cov- 
erslips and, before they built a confluent monolayer, were washed with PBS and fixed with acetone at $-20^{\circ} \mathrm{C}$ for $10 \mathrm{~min}$, followed by inhibition of endothelial peroxidase activity with $0.3 \% \mathrm{H}_{2} \mathrm{O}_{2}$ in ethanol and three washing steps in TRIS buffered saline (TBS). After blocking of unspecific binding with $0.5 \%$ BSA in TBS for $30 \mathrm{~min}$ and rinsing, specimens were incubated with 1:50 dilution of rabbit anti-human-vWF antiserum, previously shown to cross-react with the rat antigen [24], in a moist chamber for $45 \mathrm{~min}$. After a further wash, slides were incubated in a 1:50 dilution of peroxidase-conjugated porcine anti-rabbit IgG for $45 \mathrm{~min}$ at room temperature. After washing, peroxidase activity was made visible with $0.05 \%$ diaminobenzidine containing $0.015 \% \mathrm{H}_{2} \mathrm{O}_{2}$ for $5 \mathrm{~min}$ at room temperature. To exclude anti-fibronectin reactivity in the commercially available anti-vWF antiserum, aliquots were absorbed with rat plasma fibronectin immobilised on colloidal gold prior to use. Control cultures were incubated with an irrelevant rabbit hyperimmuneserum. Isolated human platelets (positive control) as well as the fibroblastoma cell line L929 and isolated rat alveolar macrophages were tested as negative controls. A rat vascular endothelium specific monoclonal antibody Ox43 [27] and the rat brain endothelium specific monoclonal antibody $\mathrm{Ox} 2$ [28] which was previously shown to specifically stain the microvascular endothelium of the endocrine pancreas only [24] were used in a 1:10 dilution. An anti-ratCD 31 antibody was used in a dilution of 1:50. Peroxidase-conjugated goat anti-mouse $\operatorname{IgG}$ was diluted 1:30 prior to use. The $e c$ NOS-specific monoclonal antibody was used in a 1:100 dilution. Otherwise incubations were done as described above.

Experimental design. All measurements were done with cells in passages 3-8. Endothelial cells $\left(10^{5}\right)$ were incubated in 24well tissue culture plates for $24 \mathrm{~h}$ (in a humidified incubator at $37^{\circ} \mathrm{C}$ in a $95 \%$ air:5\% $\mathrm{CO}_{2}$ atmosphere) in $600 \mu \mathrm{RPMI} 1640$ with $20 \% \mathrm{FCS}$ and $1,4,11$, or $20 \mathrm{mmol} / \mathrm{l}$ glucose. For inducible nitric oxide synthase expression and activity, endothelial cell cultures were incubated with the cytokine-mix $425 \mu \mathrm{mol} / \mathrm{l} \mathrm{IL-}$ $1 \beta$ plus $170 \mu \mathrm{mol} / 1 \mathrm{TNF} \alpha$ plus $70 \mu \mathrm{mol} / \mathrm{l} \mathrm{IFN} \gamma$ for $24 \mathrm{~h}$ which had been shown previously to result in the maximum $i$ NOS activity [21]. After the incubation, nitrite was determined in culture supernatants using the diazotization reaction as modified [29] and $\mathrm{NaNO}_{2}$ as standard. Citrulline was determined using a colorimetric assay [30]. The assay uses the reaction with diacetyl monoxime $(5 \mathrm{~g} / \mathrm{l})$ in the presence of sulphuric acid $(25 \%)$, phosphoric acid $(20 \%)$ and $\mathrm{FeCl}_{3}(250 \mathrm{mg} / \mathrm{l})$. Culture supernatants $(400 \mu \mathrm{l})$ were incubated with $100 \mu \mathrm{l}$ urease $(60$ $\mathrm{U} / \mathrm{ml}$ ) for $30 \mathrm{~min}$. The mixture was deproteinized by adding trichloroacetic acid (TCA) to a final concentration of at least $5 \%$. After centrifugation, $500 \mu \mathrm{l}$ of the supernatant and $3 \mathrm{ml}$ of the chromogenic solution were boiled for $5 \mathrm{~min}$, cooled to room temperature and absorbance measured at $530 \mathrm{~nm}$ in an ELISA-reader. From resulting extinctions controls with medium and respective additives but without cells were subtracted. Extinctions were calculated against a citrulline standard.

Polymerase chain reaction (PCR). Total cellular RNA, prepared from cytokine-stimulated $(24 \mathrm{~h}$ incubation of cells with the cytokine-mix $425 \mu \mathrm{mol} / 1 \mathrm{IL}-1 \beta$ plus $170 \mu \mathrm{mol} / 1 \mathrm{TNF} \alpha$ plus $70 \mu \mathrm{mol} / \mathrm{l}$ IFN $\gamma)$ and resident endothelial cells ( $1 \mu \mathrm{g}$ each) was used for cDNA synthesis. The rat $e c$ NOS sequence is currently not available. We therefore searched for a general NOS primer by multialignment of the available NOS-sequences. The general NOS primer was used as antisense primer in PCR. To exclude that positive signals were derived from $i$ NOS expression in these cells, the same probes after reverse transcription were in addition subjected to $i$ NOS-specific PCR. Reverse transcription was carried out at $55^{\circ} \mathrm{C}$ for 45 min using the oligo
$\mathrm{dT}_{16}$-primer. The cDNA (500 ng each) was used as template for PCR either primed by the sense oligonucleotides GGCCGCTTCGACGTGCTGCCT (sense; consensus sequence of rat $i$ NOS cDNA, bases 1074-1094 [31], and human ecNOS cDNA, bases 870-890 [32]) and ACTTCCTCCAGGATGTTGTA (antisense; consensus sequence of rat $i$ NOS cDNA, bases 1341-1360, and human ecNOS cDNA, bases 1137-1156) for ecNOS cDNA amplification or primed by the oligonucleotides TGATGTGCTGCCTCTGGTCT (sense: bases 1082-1101 of rat $i$ NOS cDNA) and ACTTCCTCCAGGATGTTGTA (antisense; consensus sequence of rat $i$ NOS cDNA, bases 1341-1360, and human ecNOS cDNA, bases 1137-1156) for specific rat $i$ NOS amplification. The oligonucleotides ACCACAGTCCATGCCATCAC (sense; rat GAPDH-cDNA bases 586-605) and TCCACCACCCTGTTGCTGTA (antisense; rat GAPDH-cDNA bases: 1049-1068) were used for specific rat GAPDH-cDNA amplification [33]. Polymerase chain reaction was carried out following standard protocols, 35 cycles with $30 \mathrm{~s}$ at $94^{\circ} \mathrm{C}$, $1 \mathrm{~min}$ at $55^{\circ} \mathrm{C}, 1 \mathrm{~min}$ at $72^{\circ} \mathrm{C}$ and a final incubation step at $72^{\circ} \mathrm{C}$ for $10 \mathrm{~min}$ was done for $e c \mathrm{NOS}$ or $i \mathrm{NOS}$ amplification, and 28 cycles with $30 \mathrm{~s}$ at $94^{\circ} \mathrm{C}, 30 \mathrm{~s}$ at $60^{\circ} \mathrm{C}, 30 \mathrm{~s}$ at $72^{\circ} \mathrm{C}$ and a final incubation step at $72^{\circ} \mathrm{C}$ for 10 min was done for GAP$\mathrm{DH}$ amplification. An aliquot of each reaction was subjected to electrophoresis on $2 \%$ agarose gels. Bands were made visible by ethidium bromide staining. Densitometric analysis of the amplification products was done by using the Kodak 1D software (Kodak, Stuttgart, Germany) on digital images.

Sequence-analysis of the amplified ecNOS and iNOS products. Polymerase chain reaction products were purified via Qiagen columns (Qiagen, Hilden, Germany) and cycle sequenced using the ABI BigDye Terminator Kit (Perkin-Elmer, Weiterstadt, Germany) with ecNOS forward and reverse amplification primers on an automated sequencer (ABI 310 from Perkin-Elmer).

Statistical analysis. Data are given as arithmetical means \pm SD. Values were calculated using analysis with Student's $t$ test (two-tailed for independent samples).

\section{Results}

Characterisation of cultured rat endothelial cells from different tissues obtained from different rat-strains. Rat aorta endothelial cells (AEC) and islet capillary endothelial cells (IEC) were obtained by outgrowth from aorta segments or from isolated rat islets on a collagen matrix in the presence of endothelial growth supplement as described in Material and methods and routinely cultured on non-coated plastic culture plates in the presence of RPMI 1640 plus $20 \%$ FCS with glucose concentrations indicated. Morphologically endothelial cells growing under these conditions were a variable exactly as shown in previous publications [21, 24, 34-37]. All endothelial cells were cultured under identical conditions. Immunocytochemistry of aortic and islet endothelial cells with the monoclonal antibodies $\mathrm{Ox} 2, \mathrm{Ox} 43$ as well as anti-ecNOS, and anti-CD31 and an antiserum raised against vWF confirmed that cultures consisted of endothelial cells, as the respective expression pattern of cellular antigens is not met by any other cell type (Fig. 1). More- 


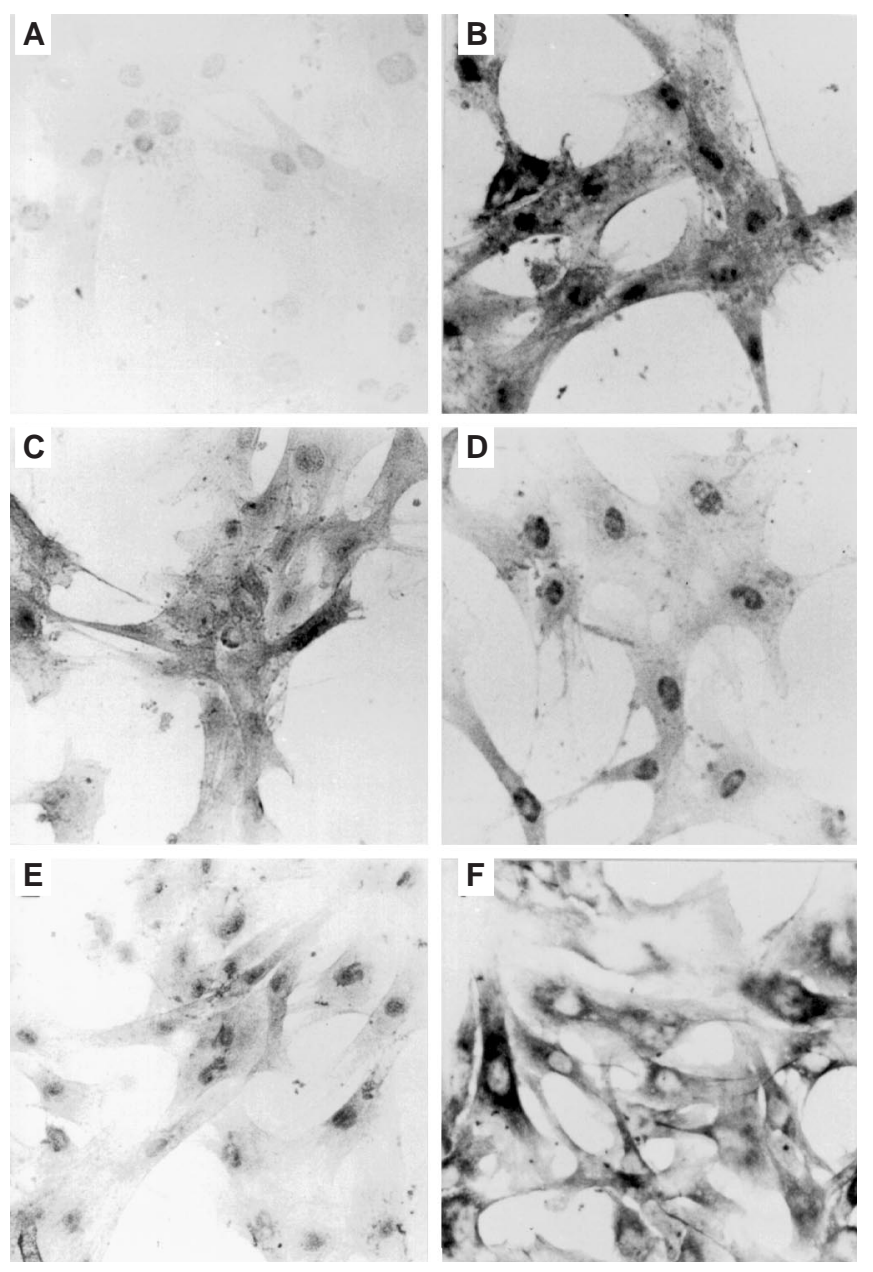

Fig. 1A-F. Characterisation of islet endothelial cell culture obtained by outgrowth from isolated islets on a collagen matrix. Control cultures (A) were incubated with an irrelevant rabbit hyperimmuneserum instead of the primary antibody. Immunocytochemistry of islet endothelial cells with endothelia-specific antibodies resulted in strong anti-CD31- (B) and $\mathrm{O} \times 2$-staining $(\mathbf{C})$ whereas $\mathrm{O} \times 43$ staining $(\mathbf{D})$ was weak. Cells were consistently found positive for $e c \operatorname{NOS}(\mathbf{E})$ and strongly stained for $\mathrm{vWF}(\mathbf{F})$. This antigenic expression pattern also proves that cultures consisted of pure endothelial cells, as the respective staining patterns of the cell specific markers were found in all cells of the different IEC-cultures. Cells were counterstained with haematoxilin. Magnification $\times 650$

over, the respective staining patterns were found with all cell cultures used here as an indication of purity.

Nitrite and citrulline concentrations in culture supernatants of endothelial cells as an indicator for NOS activity. Resident or cytokine activated endothelial cell cultures were maintained in culture media containing 1,4 , or $11 \mathrm{mmol} / 1$ glucose, respectively. The concentrations of nitrite and citrulline as the two stable reaction products of the arginine/NO pathway were determined in culture supernatants $24 \mathrm{~h}$ after fresh medium addition with or without cytokines and were calculated as nmol $/ 10^{5}$ cells $\times 24 \mathrm{~h}$.
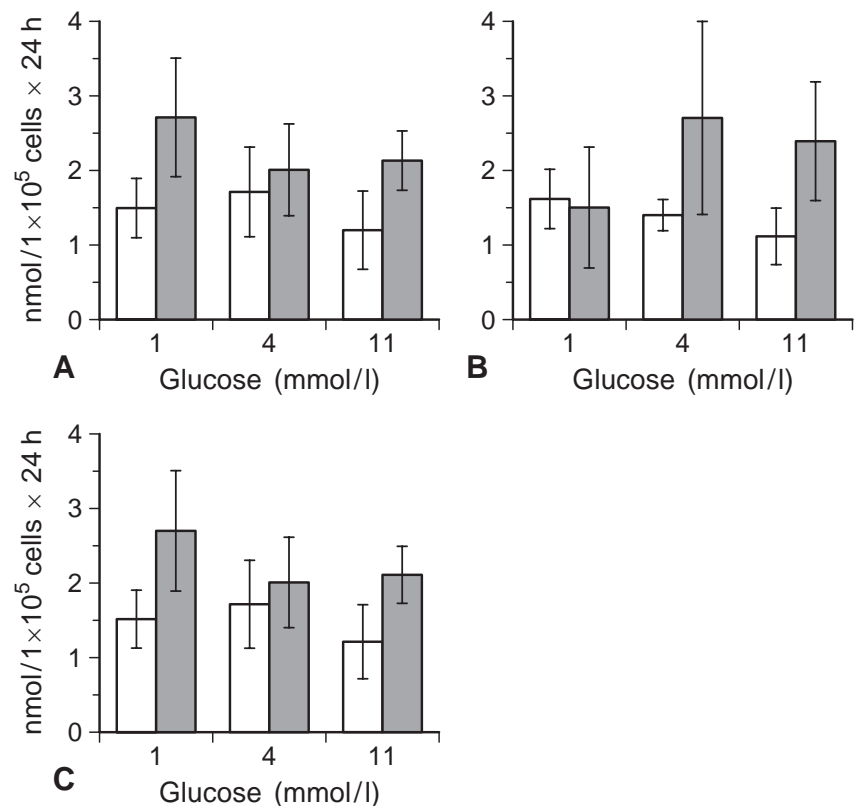

Fig. 2 A-C. Effect of glucose concentrations on constitutive nitrite and citrulline production in aorta endothelial cell (AEC) culture supernatants. After $24 \mathrm{~h}$ of culture $\left(1 \times 10^{5}\right.$ cells each) no differences in nitrite (white bars) or citrulline (black bars) production between rat strains were seen. A Wistar rats, B BBdp rats and $\mathbf{C}$ BBdr rats were maintained at various glucose concentrations and no correlation to glucose concentration is found with AEC. Values are the means \pm SD of 4 to 18 individual experiments

As shown previously by others nitrite and citrulline is not found in equimolar amounts since nitric oxide is oxidised to nitrite and nitrate in a varying ratio depending on culture time and conditions, whereas citrulline is a stable end product with no reuse in the presence of arginine [38, 39]. Resident AEC showed comparatively little ecNOS-mediated nitrite and citrulline production independent of glucose concentration and there were no differences between strains (Fig. 2).

In supernatants of IEC from Wistar rats (Fig.3A) grown in the presence of $1 \mathrm{mmol} / 1$ glucose, nitrite and citrulline concentrations were not significantly different from AEC cultures. Culturing IEC at higher glucose concentrations resulted in pronounced increases of nitrite and citrulline, strongly and positively correlating with the respective glucose concentration. Between $1 \mathrm{mmol} / \mathrm{l}$ and $11 \mathrm{mmol} / \mathrm{l}$ of glucose nitrite and citrulline concentrations increased by a factor of 5, as reported previously [24].

A completely different pattern of ecNOS activities in response to glucose concentrations was seen in IEC from any of the BB rats. The IEC from diabetes-resistant BBdr rats (Fig. 3C) and from BBdp rats (Fig. 3B) showed no significant correlation between medium glucose concentrations and nitrite or citrulline production.

Compared with IEC from the other rat strains, those from all BBdp rats examined (Fig. 3B) show a 

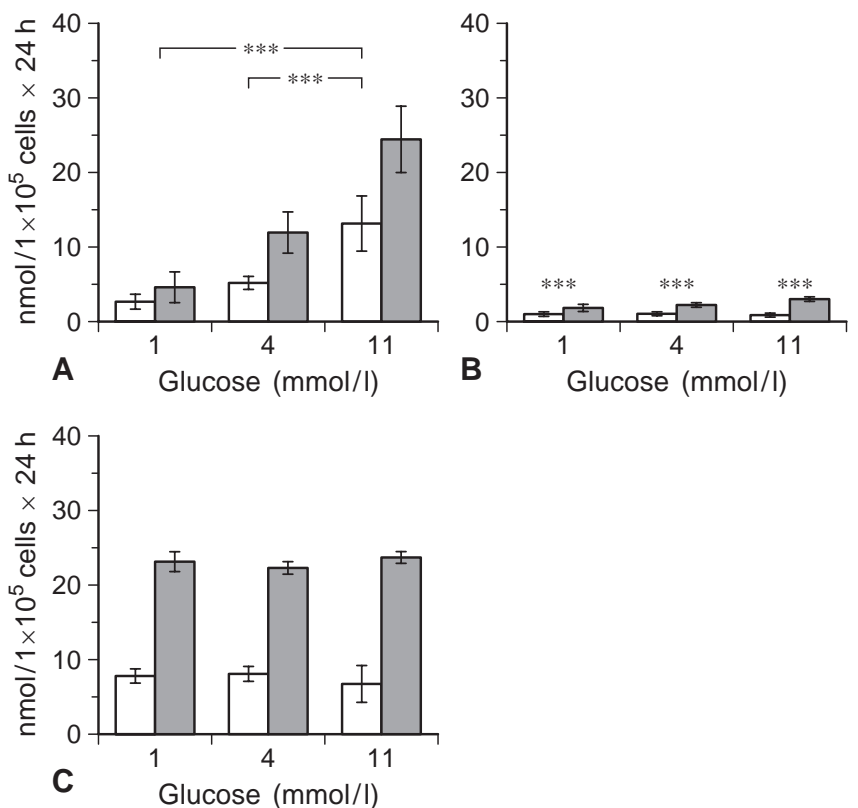

Fig.3 A-C. Effect of glucose concentrations on constitutive nitrite and citrulline production in islet endothelial cells (IEC) culture supernatants. After $24 \mathrm{~h}$ of culture $\left(1 \times 10^{5}\right.$ cells each) a strong correlation between nitrite (white bars) or citrulline (black bars) production and glucose concentration is found with IEC obtained from Wistar rats (A) but not with IEC obtained from $\mathrm{BBdr}$ rats $(\mathbf{C})$ or $\mathrm{BBdp}$ rats $(\mathbf{B})$. Statistical differences in nitrite and citrulline concentrations measured in IEC cultures from Wistar rats between 1 and $11 \mathrm{mmol} / \mathrm{l}$ glucose (A) were $(p<0.0001 * * *)$. Additionally, resident IEC obtained from young BBdp rats $(\mathbf{B})$ showed a diminished nitrite and citrulline production at 1,4 , and $11 \mathrm{mmol} / \mathrm{l}$ glucose than the respective probes of IEC from the other rat strains $(\mathbf{A}, \mathbf{C})(* * *$, $p<0.0001)$. Values are the means \pm SD of 4 to 24 individual experiments

pronounced decreased constitutive NO formation at every glucose concentration used. At any glucose concentration resting islet endothelial cells from prediabetic BBdp rats produced less NO than those of any other rat strain. At physiological glucose concentrations only the $\mathrm{BBdp}$ rat derived IEC are abnormally low in their ecNOS activity whereas IEC from BBdr show ecNOS activities comparable to those obtained with Wistar rats (Fig. 4A).

Furthermore, equivalent effects of glucose on activity of the inducible nitric oxide synthase and an impaired NO-formation in IEC obtained from prediabetic BBdp rats were found with cytokine activated cell cultures (Fig. 4B) whereas with cytokine activated AEC again no differences between the various rat strains were observed (data not shown).

Neither growth rates nor viabilities of AEC and IEC showed significant differences between the different rats.

ecNOS-specific mRNA expression. We carried out reverse transcription (RT)-PCR with total RNA ex-
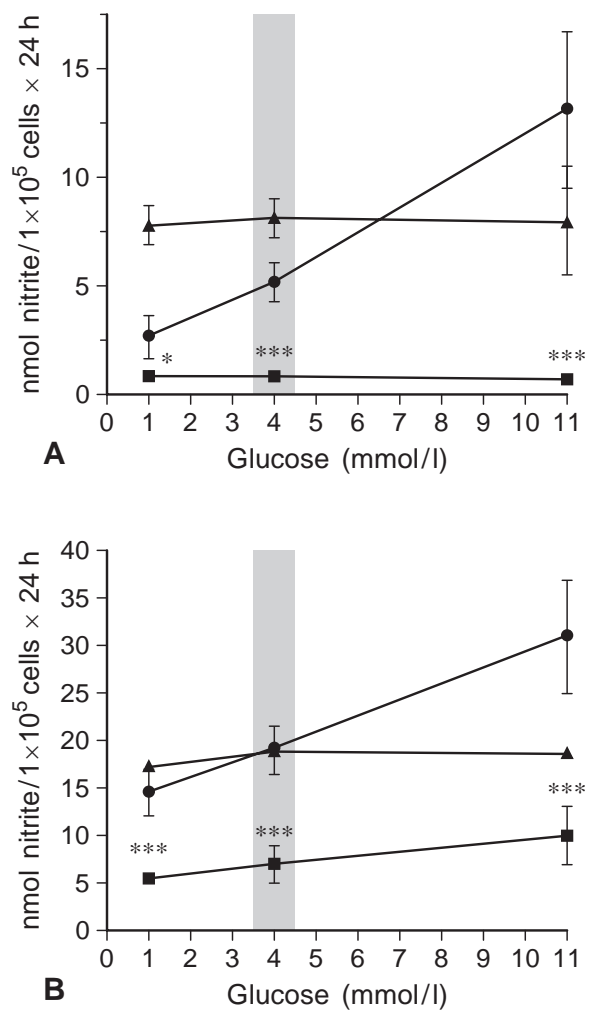

Fig. 4A, B. Comparison of ecNOS and iNOS activities and their modulation by glucose concentrations in the various rat strains. A At any given glucose concentration non-activated, resident islet endothelial cells from BBdp rats $(\square)$ produce less $(*, p<0.01$; ***, $p<0.0001)$ NO than those of any other rat strain. At physiological glucose concentrations (grey area) only the young BBdp rat derived IEC are abnormally low in their ecNOS activity whereas IEC from BBdr (A) show ecNOS activities similar to those obtained with Wistar rats $(\boldsymbol{O})$. Values represent the means \pm SD of 24 individual experiments. B With cytokine activated islet endothelial cells similar effects are observed. Again, at any given glucose concentration activated islet endothelial cells from BBdp rats $(\square)$ produce less $(* * *, p<0.0001) \mathrm{NO}$ than those of any other rat strain and at physiological glucose concentrations (grey area) only the young BBdp rat derived IEC are abnormally low in their NO formation whereas IEC from $\mathrm{BBdr}(\boldsymbol{\Delta})$ show nitrite accumulations similar to those obtained with Wistar rats $(\mathbf{O})$. Note the highly increased nitrite production in $\mathbf{B}$. Values represent the means \pm SD of 24 individual experiments

tracted from resident or cytokine activated $(425 \mu \mathrm{mol} / 1$ IL- $1 \beta$ plus $170 \mu \mathrm{mol} / 1$ TNF $\alpha$ plus $70 \mu \mathrm{mol} / \mathrm{l}$ IFN $\gamma$ ) IEC obtained from Wistar rats and young BBdp rats grown in culture medium containing $1 \mathrm{mmol} / \mathrm{l}, 4 \mathrm{mmol} / \mathrm{l}$ and $11 \mathrm{mmol} / \mathrm{l}$ glucose. The PCR was primed by oligonucleotides for specific $i$ NOS amplification (Fig. 5B) or $i$ NOS plus ecNOS-specific oligonucleotides to detect rat ecNOS mRNA (Fig. 5A). With $i$ NOS-specific priming, no signal was found in any of the non-activated, resident cultures, whereas the consensus sequence primers for $i$ NOS plus $e c$ NOS gave a signal in all IEC cultures examined (Fig. 5A). Thus, resting endothelial cells do not ex- 

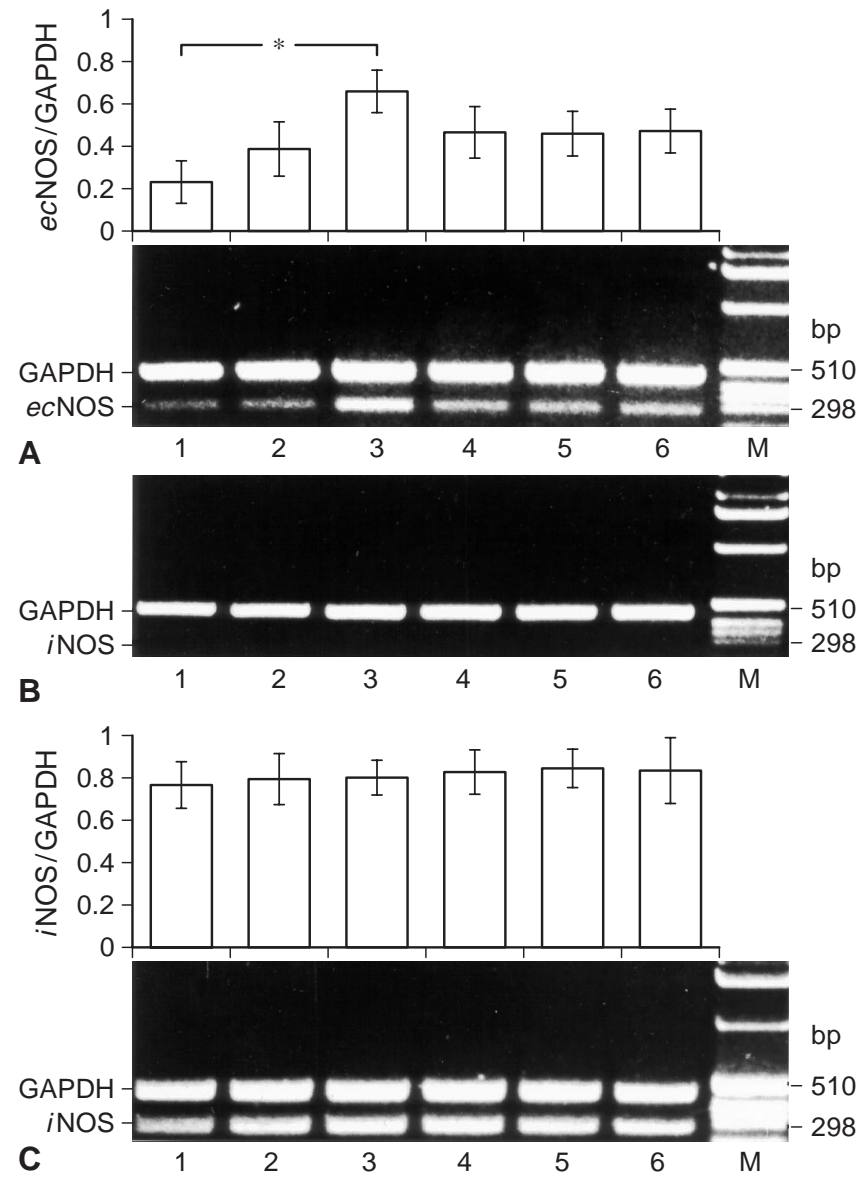

Fig.5A-C. Detection of iNOS- and iNOS plus ecNOS-specific mRNA in islet endothelial cells by PCR. In resident IEC an amplification product was obtained only by priming with the $i$ NOS plus ecNOS specific oligonucleotides (A). These amplification products represent the ecNOS specific product $(287$ $\mathrm{bp})$, since priming with $i$ NOS-specific oligonucleotides (B) gave negative results. A significant $(*, p<0.01)$ and reproducible tendency for increasing amounts of PCR product with increasing glucose concentration $(1 \mathrm{mmol} / \mathrm{l}$ in lanes 1 and 4 , $4 \mathrm{mmol} / \mathrm{l}$ in lanes 2 and $5,11 \mathrm{mmol} / \mathrm{l}$ in lanes 3 and 6 was found with resident IEC obtained from Wistar rats (lanes 1-3) but not with resident IEC from the BBdp animals (lanes 4-6). Lane 7 represents DNA size marker. $C$ shows the positive control for $i$ NOS-mRNA-expression $(279 \mathrm{bp})$ in cytokine activated $(24 \mathrm{~h}$ incubation of cells with the cytokine-mix Wistar-IEC (lanes 1-3) and young normoglycaemic BBdp rats (lanes 4-6). Again, cells were grown in medium containing $1 \mathrm{mmol} / \mathrm{l}$ (lanes 1 and 4), $4 \mathrm{mmol} / \mathrm{l}$ (lanes 2 and 5) and $11 \mathrm{mmol} / \mathrm{l}$ (lanes 3 and 6) glucose concentration. The upper bands in lanes 1-6 of the figures represent the specific GAPDH-cDNA amplification products $(483 \mathrm{bp})$ of the corresponding cells. Bars represent the means \pm SD of GAPDH:ecNOS or GAPDH: $i$ NOS ratios of 3 individual experiments as obtained by densitometric analysis

press the $i$ NOS and the consensus sequence-specific PCR can be used with resting endothelial cells for $e c$ NOS-mRNA amplification. This is further supported by sequence analysis. Amplification products obtained show a homology of $80 \%$ with rat $i$ NOS-sequence, $85 \%$ with human $i$ NOS sequence, $76 \%$ with mouse $i$ NOS sequence, $92 \%$ with human $e c$ NOS sequence and $95 \%$ with mouse $e c$ NOS sequence. The specifically primed amplification product of the $i$ NOS in cytokine activated rat endothelial cells, however, had a $100 \%$ homology with the known rat $i$ NOS-sequence.

Compared with the signal intensity of the amplification product for the house-keeping gene GAPDH, a reproducible relative increase in the amount of the $e c$ NOS amplification products with increasing glucose concentrations was found in IEC from Wistar rats but not in IEC from BBdp rats (Fig. 5A) or sham treated resident IEC obtained from BBdr rats (data not shown). In contrast, after cytokine-activation a dominant $i$ NOS-signal was seen in all endothelial cell cultures examined (Fig. 5C).

\section{Discussion}

Infiltration of islets by macrophages and lymphocytes prior to diabetes development is a prerequisite for disease manifestation and has been observed in all animal models $[3,40]$. Early during the inflammatory process morphological and functional changes in the microvascular system of the islets become apparent and increased permeability of the islet capillary bed appears to facilitate the extravasation of immune mediators and inflammatory cells [11]. Furthermore, experimental suppression of enhanced vascular permeability inhibits the development of diabetes [41].

Adhesion of leucocytes to microvascular endothelium and subsequent migration into inflamed tissue are rate-limiting steps in the initiation and maintenance of infiltrative processes associated with inflammatory responses $[42,43]$. The basis for the adhesive interactions that occur between leucocytes and endothelial cells during inflammation is the interaction of adhesive glycoproteins expressed on the surface of both leucocytes and endothelial cells [44, 45]. There is increasing circumstantial evidence that NO exerts anti-adhesive activity. Nitric oxide has been shown to block platelet aggregation and to reduce platelet adhesion to endothelial cell monolayers [16, 17]. It inhibits leucocyte aggregation in vitro and in addition inhibitors of NO production greatly enhance leucocyte adherence to and migration through the endothelium [22] in vivo. These results indicate that NO produced by endothelia has an important physiological role in regulating leucocyte-endothelial cell adhesion and inflammatory processes [23].

We recently found a unique pattern of $e c$ NOS activity in rat islet endothelial cells (IEC) that exhibited a close positive correlation with the glucose concentration present [24]. Indeed, this effect appears to be an organ-specific control of constitutive NO formation, as rat aorta endothelial cells cultured under identical conditions do not show this glucose sensitiv- 
ity. It is tempting to speculate that this behaviour contributes to first-phase insulin secretion recently shown to be NO mediated [46]. In addition, increases in $e c \mathrm{NOS}$-mediated NO production may represent a physiological control of leucocyte adhesion during hyperglycaemia counteracting the hyperglycaemia induced increases in leucocyte binding to endothelial cells [47]. In this study we show that IEC obtained from $\mathrm{BB}$ rats with largely different probabilities for disease manifestation exhibit no glucose regulation of their ecNOS activities. More importantly, we found a reproducible and pronounced dysfunction of the ecNOS-activity in IEC obtained from young diabetes-prone BBdp rats. The results obtained show that at any given glucose concentration islet endothelial cells from BBdp rats produce less NO than those of the other rat strains. At physiological glucose concentrations of around $4 \mathrm{mmol} / \mathrm{l}$ of glucose IEC from BBdr show ecNOS activities similar to those obtained with Wistar rats whereas the diabetes prone BBdp rat derived IEC are abnormally low in their ecNOS activities. These data are consistent with recent studies using coronary microvascular endothelial cells isolated from diabetic BB rats in which decreased basal NO production was observed based on measurements of nitrate production [48].

We have shown with our experiments that glucosedependent increases in nitrite and citrulline production are not attributable to $i$ NOS induction as under these non-activating conditions no $i N O S$-specific gene product was found, although all endothelial cells will express iNOS upon cytokine mediated activation. The rat strain-specific differences in nitrite and citrulline production of resident cells can be attributed to different $e c$ NOS activities only as is further supported by semi-quantitative RT-PCR. Although this method does not allow for true quantification of mRNA content, increases in signal intensities in resting Wistar IEC are readily seen when all probes are processed in parallel and compared with the parallel amplification product of the house-keeping gene $G A P D H$.

The differences in $e c$ NOS activities were found to be stable in in vitro cell cultures for at least 50 cell cycles, i.e. a mean increase in cell number by a factor of about 6 per passage and cells were used for up to 8 passages. This suggests a genetic difference in gene regulation.

A number of different mechanisms could be involved in the strongly decreased ecNOS activity in IEC obtained from the BBdp rats. Our findings of a dramatic decrease in nitrite formation in resting as well as in cytokine activated IEC from prediabetic BBdp rats favour the assumption that an unknown defect in arginine use for NO synthesis could be responsible. Indeed, an impaired arginine metabolism and NO synthesis in coronary endothelial cells of BBdp rats was described recently and it was also shown that supplementation with arginine can reverse endothelial dysfunction [48].

In conclusion, in islet capillary endothelial cells obtained from young normoglycaemic BBdp rats we found a defect in glucose-mediated regulation of $e c$ NOS activity at normohyperglycaemic and hyperglycaemic glucose concentrations which correlates with the probability of disease manifestation as islet endothelia from BBdr rats show pronounced differences. Thus, this regulatory defect may represent a crucial factor in the manifestation process of Type I diabetes.

Acknowledgements. We thank C.-M. Wilkens, M. Lovrencic and U. Lammersen for technical assistance, and S. Wenzel-Unger and M. Turken for photographic assistance. This work was supported by a grant from the Deutsche Forschungsgemeinschaft (Ko806/6-1 to V. K.-B.).

\section{References}

1. Mandrup-Poulsen T, Helquist S, Wogensen LD et al. (1990) Cytokines and free radicals as effector molecules in the destruction of pancreatic beta cells. Curr Top Microbiol Immunol 164: 169-193

2. Cooke A (1990) An overview on possible mechanisms of destruction of the insulin-producing beta cell. Curr Top Microbiol Immunol 164: 125-142

3. Hanenberg H, Kolb-Bachofen V, Kantwerk-Funke G, Kolb $\mathrm{H}$ (1989) Macrophage infiltration precedes and is a prerequisite for lymphocytic insulitis in pancreatic islets of pre-diabetic BB-rats. Diabetologia 32: 126-134

4. Mandrup-Poulsen T, Bendtzen K, Nerup J, Egeberg J, Nielsen JH (1986) Mechanisms of pancreatic islet-destruction: dose-dependent cytotoxic effect of soluble mononuclear cell mediators on isolated islets of Langerhans. Allergy (Cph) 41: 250-259

5. Prober JS, Cotran RS (1990) The role of endothelial cells in inflammation. Transplantation 50: 537-544

6. Osborn L (1990) Leukocyte adhesion to endothelium in inflammation. Cell 62: 3-6

7. Dolgov VV, Zaikina OE, Bondarenko MF, Repen VS (1982) Aortic endothelium of alloxan diabetic rabbits: a quantitative study using scanning electron microscopy. Diabetologia 22: 338-343

8. Pugliese G, Tilton RG, Williamson JR (1991) Glucose-induced metabolic imbalances in the pathogenesis of diabetic vascular disease. Diabetes Metab Rev 7: 35-59

9. Tucker BJ (1990) Early onset of increased transcapillary albumis escape in awake diabetic rats. Diabetes 39: 919-923

10. Arbogast BW, Berry DL, Newell CL (1984) Injury of arterial endothelial cells in diabetic, sucrose-fed and aged rats. Atherosclerosis 51: 31-45

11. Majno G, Joris I, Handler ES, Desemone J, Mordes JP, Rossini AA (1987) A pancreatic venular defect in the BB/ Wor rat. Am J Pathol 128: 210-215

12. Hänninen A, Salmi M, Simell O, Jalkanen S (1993) Endothelial cell-binding properties of lymphocytes infiltrated into human diabetic pancreas. Diabetes 42: 1656-1662

13. Jones RL, Peterson CM (1981) The fluid phase of coagulation and the accelerated atherosclerosis of diabetes mellitus. Diabetes 30 [Suppl 2]: 33-38 
14. Mustard JF, Packham MA (1984) Platelets and diabetes mellitus. N Engl J Med 319: 665-667

15. Rees D, Palmer R, Moncada S (1989) Role of endothelium-derived nitric oxide in the regulation of blood pressure. Proc Natl Acad Sci USA 86: 3375-3381

16. Radomski MW, Palmer RMJ, Moncada S (1987) Comparative pharmacology of endothelium-derived relaxing factor, nitric oxide and prostacyclin in platelets. Br J Pharmacol 92: 181-187

17. Radomski MW, Pamer RMJ, Moncada S (1987) Endogenous nitric oxide inhibits human platelet adhesion to vascular endothelium. Lancet ii: $1057-1058$

18. Baldwin WM (1982) The symbiosis of immunocompetent and endothelial cells. Immunol Today 3: 267-272

19. Cotran RS, Pober JS (1989) Effects of cytokines on vascular endothelium: their role in vascular and immune injury. Kidney Int 35: 969-975

20. Zimmerman GA, Prescott SM, McIntyre TM (1992) Endothelial cell interactions with granulocytes: tethering and signal molecules. Immunol Today 13: 93-98

21. Suschek C, Rothe H, Fehsel K, Enczmann J, Kolb-Bachofen V (1993) Induction of a macrophage-like nitric oxide synthase in cultured rat aortic endothelial cells. J Immunol 151: 3283-3291

22. Moncada S, Palmer RMJ, Higgs EA (1991) Nitric oxide: physiology, pathophysiology and pharmacology. Pharmacol Rev 43: 109-142

23. Kubes P, Suzuki M, Granger DN (1991) Nitric oxide: an endogeneous modulator of leukocyte adhesion. Proc Natl Acad Sci USA 88: 4651-4655

24. Suschek C, Fehsel K, Kröncke K-D, Sommer A, KolbBachofen V (1994) Primary cultures of rat capillary endothelial cells: constitutive and cytokine-inducible macrophage-like nitric oxide synthases are expressed and activities regulated by glucose concentration. Am J Pathol 145: 685-695

25. Appels B, Burkart V, Kantwerk-Funke G, Funda J, KolbBachofen V, Kolb H (1988) Spontaneous cytotoxicyty of macrophages against pancreatic islets and insulinoma cells. J Immunol 142: 3803-3808

26. Finter NB (1969) Dye uptake methods of assessing viral cytopathogenicity and their application to interferon assays. J Gen Virol 5: 419-425

27. Robinson AP, White TM, Mason DW (1986) MRC-O × 43: a monoclonal antibody which reacts with all vascular endothelium in the rat except that of brain capillaries. J Immunol 57: 231-237

28. Barclay AN (1981) Differential reticular elements in rat lymphoid tissue identified by localisation of la, Thy-1, and MRC-Ox 2 antigens. Immunology 44: 727-736

29. Wood KS, Buga GM, Byrns RE, Ignarro LJ (1990) Vascular smooth muscle-derived relaxing factor (MDRF) and its close similarity to nitric oxide. Biochem Biophys Res Commun 170: 80-87

30. Boyde TCR, Rahmatullah M (1980) Optimization of conditions for the colorimetric determination of citrulline, using diacetyl monoxime. Anal Biochem 107: 424-431
31. Nunokawa Y, Ishida N, Tanaka S (1993) Cloning of inducible nitric oxide synthase in rat vascular smooth muscle cells. Biochem Biophys Res Commun 191: 89-94

32. Marsden PA, Schapert KT, Chen HS et al. (1992) Molecular cloning and characterization of human endothelial nitric oxide synthase. FEBS Lett 307: 287-293

33. Sirsjö A, Söderkvist P, Sundquist T, Calsson M, Öst M, Gidlöf A (1994) Different induction mechanisms of mRNA for inducible nitric oxide synthase in rat smooth muscle cells in culture and in aorta strips. FEBS Lett 338: 191-196

34. McGuire PG, Orkin RW (1987) Isolation of rat aortic endothelial cells by primary explant techniques and their phenotypic modulation by defined substrates. Lab Invest 57: 94-104

35. Karasek MA (1989) Microvascular endothelial cell culture. J Invest Dermatol 93: 33S-38S

36. Hewett PW, Murray JC (1993) Human lung microvessel endothelial cells: isolation, culture, and characterisation. Microvasc Res 46: 89-102

37. Montesano R, Orci L, Vassalli P (1985) Human endothelial cell cultures: phenotypic modulation by leucocyte interleukins. J Cell Physiol 122: 424-434

38. Stuehr DJ, Marletta MA (1987) Synthesis of nitrite and nitrate in murine macrophage cell lines. Cancer Res 47: 5590-5594

39. Marletta MA, Yoon PS, Iyengar R, Leaf CD, Wishnok JS (1988) Macrophage oxidation of L-arginine to nitrite and nitrate: nitric oxide is an intermediate. Biochemistry 27: 8706-8711

40. Kolb-Bachofen V, Kolb H (1989) A role for macrophages in the pathogenesis of type 1 diabetes. Autoimmunity 3: 145-155

41. Schwab E, Burkart V, Freytag G, Kiesel U, Kolb H (1986) Inhibition of immune-mediated low-dose streptozotocin diabetes by agents which reduce vascular permeability. Immunopharmacology 12: 17-21

42. Shimizu Y, Newman W, Tanaka Y, Shaw S (1992) Lymphocyte interaction with endothelial cells. Immunol Today 13: 106-112

43. Duijvestijn AM, Hamann A (1989) Mechanisms and regulation of lymphocyte migration. Immunol Today 10: 23-29

44. Springer T (1990) Adhesion receptors of the immune system. Nature 346: 425-434

45. Butcher EC (1991) Leukocyte-endothelial cell recognition: three (or more) steps to specificity and diversity. Cell 67: 1033-1036

46. Spinas GA, Laffranchi R, Francoys I, David I, Richter C, Reinecke M (1998) The early phase of glucose-stimulated insulin secretion requires nitric oxide. Diabetologia 41: 292-299

47. Kim JA, Berliner JA, Natarajan RD, Nadler JL (1994) Evidence that glucose increases monocyte binding to human aortic endothelial cells. Diabetes 43: 1103-1107

48. Wu G, Meininger CJ (1995) Impaired arginine metabolism and NO synthesis in coronary endothelial cells of the spontaneously diabetic BB rat. Am J Physiol 269 (Heart Circ Physiol 38): H1312-H1318 